\title{
Changes in neutrophil/lymphocyte and platelet/lymphocyte ratios after chemotherapy correlate with chemotherapy response and prediction of prognosis in patients with unresectable gastric cancer
}

\author{
FEN WANG ${ }^{1,2^{*}}$, ZE-YI LIU $^{3,4^{*}}$, YOU-YOU XIA ${ }^{5,6^{*}}$, CHONG ZHOU $^{7}$, XIAO-MING SHEN ${ }^{8}$, \\ XIANG-LI LI ${ }^{9}$, SHU-GUANG HAN ${ }^{9}$, YAN ZHENG ${ }^{8}$, ZHONG-QI MAO $^{10}$, \\ FEI-RAN GONG ${ }^{11}$, MIN TAO ${ }^{1,12-14}$, LIAN LIAN $^{1,8}$ and WEI LI ${ }^{1,12,14}$ \\ Departments of ${ }^{1}$ Oncology, ${ }^{2}$ Nursing, ${ }^{3}$ Respiratory Medicine, The First Affiliated Hospital of Soochow University; \\ ${ }^{4}$ Institute of Respiratory Diseases, Soochow University, Suzhou; ${ }^{5}$ Department of Radiation Oncology, Lianyungang \\ First People's Hospital, Lianyungang; ${ }^{6}$ The Fourth Clinical Medical College, Nanjing Medical University, Nanjing; \\ ${ }^{7}$ Department of Radiation Oncology, Xuzhou Central Hospital, Xuzhou; ${ }^{8}$ Department of Oncology, \\ Suzhou Xiangcheng People's Hospital; ${ }^{9}$ Department of General Surgery, Suzhou Xiangcheng People's Hospital; \\ Departments of ${ }^{10}$ Minimally Invasive Surgery and ${ }^{11}$ Hematology, The First Affiliated Hospital of Soochow University; \\ ${ }^{12}$ Jiangsu Institute of Clinical Immunology; ${ }^{13}$ Institute of Medical Biotechnology, ${ }^{14}$ PREMED Key Laboratory \\ for Precision Medicine, Soochow University, Suzhou, Jiangsu, P.R. China
}

Received July 16, 2015; Accepted September 15, 2015

DOI: $10.3892 / \mathrm{ol} .2015 .3783$

\begin{abstract}
The aim of the study was to investigate the application value of neutrophil to lymphocyte ratio (NLR) and the platelet to lymphocyte ratio (PLR) in the prediction of chemotherapy response and prognosis in patients with advanced gastric cancer. In total, 120 patients with unresectable gastric cancer were included and separated into two groups according to the median values of NLR or PLR (NLR low: $<4.62$ or NLR high: $\geq 4.62$ and PLR low: $<235$ or PLR high: $\geq 235$, respectively). Low baseline NLR level correlated with improved clinicopathological characteristics, including smaller tumor size, well differentiation and less metastasis. Low baseline PLR level also associated with less metastasis. Patients with a low baseline level of NLR or PLR had an improved response to chemotherapy. Patients with a higher
\end{abstract}

Correspondence to: Dr Wei Li, Department of Oncology, The First Affiliated Hospital of Soochow University, No. 188, Shi-zi Street, Suzhou, Jiangsu, P.R. China

E-mail: liwei10@suda.edu.cn

Dr Lian Lian, Department of Oncology, Suzhou Xiangcheng People's Hospital, 1060 Huayuan Rd, Suzhou, Jiangsu, P.R. China

E-mail:dr_lianlian@163.com

"Contributed equally

Key words: gastric cancer, neutrophil to lymphocyte ratio, platelet to lymphocyte ratio baseline NLR and PLR had decreased progression-free survival (PFS) and overall survival (OS) ratios. Alterations in the NLR and PLR levels were associated with therapeutic efficacy and prognosis. The patients who remained in or switched to the low NLR level subgroup subsequent to firstline chemotherapy had an improved response and improved OS ratios, compared to the patients remaining in or switching to the high NLR level group. Similar results were observed when the PLR level was investigated. In conclusion, baseline NLR and PLR measurements, as well as changes of NLR and PLR following chemotherapy can predict the prognostic results in patients with unresectable gastric cancer.

\section{Introduction}

Gastric cancer (GC) is the fourth most common cancer and the second cause of cancer-related mortalities worldwide $(1,2)$. Countries in East Asia (including China, Japan and Korea) have a high incidence of GC (>40 cases/100,000 men). Data for individual countries have shown that GC is the most common cancer type in Japan and the second most common in China and Korea (3). Although early diagnosis and treatment improved prognosis significantly $(4,5)$, the 5-year survival rate remains at only $10-15 \%$ among individuals with advanced disease (6).

The systemic inflammatory response (SIR) is associated with the outcome of several types of cancer (7). It has been shown that neutrophils, lymphocytes and platelets are important in tumor-induced SIR (8). Based on this hypothesis, the quantification of these blood counts has been investigated in various malignant tumors as markers of SIR $(9,10)$. 
Of these markers, neutrophil to lymphocyte ratio (NLR) and platelet to lymphocyte ratio (PLR) have been identified as a promising diagnostic prospect. Investigations have demonstrated that NLR and PLR are highly repeatable, cost-effective and widely available (11). NLR is diagnostically valuable in certain pathologies characterized by systemic or local inflammatory response, such as diabetes mellitus, coronary artery disease, ulcerative colitis, inflammatory arthritis (12-14), as well as various types of cancer, including colon cancer, gastric cancer, esophageal cancer, ovarian cancer, lung cancer and breast cancer (15-20). PLR is considered to be a marker of endogenous residual anticancer preinflammatory and precoagulative response that arises in malignancies. These biomarkers combine the evident preinflammatory and precoagulative status in cancer with the endogenous residual anticancer ability (21).

The aim of the present study was to examine whether NLR and PLR served as sensitive markers and prognostic factors in patients with unresectable GC. In addition, the relationship between the changes of NLR and PLR following chemotherapy and prognosis was investigated.

\section{Materials and methods}

Subjects and inclusion criteria. The study was conducted as a retrospective investigation of GC patients that had been referred to the First Affiliated Hospital of Soochow University (Jiangsu, China) between June 2010 and 2011. Approval for the study was granted by the Medical Ethics Committees of the First Affiliated Hospital of Soochow University. Clinical and pathological records of all the patients participating in the study were reviewed periodically.

In total, 120 unresectable GC patients were included in this study. Patient characteristics are provided in Tables I and II. The mean age of the 120 patients was 68 years (range, 32-82 years), and 75 patients were male and 45 were female. The inclusion criteria were: i) patients with histologically or cytologically confirmed recurrent or metastatic GC; ii) age $>18$ years; iii) Karnofsky performance status (KPS) score of $\geq 70$; iv) patients with a predicted survival of $\geq 3$ months; v) naive to antitumor treatment or the post-operative adjuvant chemotherapy was performed $\geq 6$ months after the previous dose of chemotherapy; vi) in the case of patients scheduled for radiotherapy on the target lesion, radiotherapy was required to have been terminated for at $\geq 3$ months; vii) patients with at least one measurable lesion (at least $10 \times 10 \mathrm{~mm}$ on CT or MRI); and viii) patients who met the following laboratory criteria: white blood cells (WBC) $\geq 4.0 \times 10^{9} / 1$, absolute neutrophil count (ANC) $\geq 1.5 \times 10^{9} / 1$, platelet (PLT) $\geq 100 \times 10^{9} / 1$, serum bilirubin $\leq$ upper limit of normal (ULN), ALT, AST and ALP $\leq$ ULN x 2.5 (if without liver metastasis) or $\leq$ ULN x 5 (if with liver metastasis), urea nitrogen $\leq$ ULN x1.25, and creatinine $\leq$ ULN $\times 1.25$.

Blood samples. Peripheral venous blood (5-7 ml) was collected into a sterile ethylenediaminetetraacetic acid (EDTA) tube. The blood samples were obtained between 6:30 and 7:30 a.m. in order to standardize the known impact of circulating hormones (circadian rhythm) on the number and subtype distribution of the various white blood cell indices. Hematological parameters were analyzed within $30 \mathrm{~min}$ after collection using a hema- tology analyser (Sysmex XE-2100; Sysmex, Kobe, Japan). Neutrophil $\left(10^{3} / \mu \mathrm{l}\right)$, lymphocyte $\left(10^{3} / \mu \mathrm{l}\right)$ and platelet $\left(10^{3} / \mu \mathrm{l}\right)$ counts were recorded. The results were expressed in $10^{3} / \mu 1$. NLR and PLR were calculated as the ratio of the neutrophils and platelets to lymphocytes, respectively. Mean value was used for NLR and PLR as normal distribution was absent. The patients were divided into two groups according to the mean value of NLR or PLR [(NLR low, $<4.62$ or NLR high, $\geq 4.62$; and PLR low, $<235$ or PLR high, $\geq 235$, respectively].

Chemotherapy and evaluation. Patients received first-line chemotherapy as outlined in the National Comprehensive Cancer Network (NCCN) clinical practice guideline for GC (2006, first edition). 5-FU/leucovorin (LV), 5-FU-based, cisplatin (CDDP)-based, oxaliplatin (L-OHP)-based, taxanebased and irinotecan (CPT-11)-based, ECF treatments were employed. Computed tomography (CT) scan was performed for the assessment of response every 2 months and evaluated according to the criteria of Response Evaluation Criteria in Solid Tumors (RECIST) 1.1 (22).

The responses to chemoradiotherapy including complete remission, regression, stable disease and disease progression, as well as overall and disease-free survival were recorded. Survival time was measured from the date of chemoradiotherapy until the patient succumbed or last clinical evaluation. Following first-line chemotherapy, disease progression after chemoradiotherapy $(n=44)$ was defined as lack of response to chemoradiotherapy. By contrast, stable disease, complete response or disease regression following chemoradiotherapy was defined as response to chemoradiotherapy $(n=76)$.

Follow-up. The responses to chemotherapy including complete remission, regression, stable disease and disease progression, as well as overall and progression-free survival were recorded. Survival time was defined as the time from the date of chemoradiotherapy until the patient succumbed or last clinical evaluation. Patients were followed up regularly for 40 months. The prognostic analyses were performed to determine the progression-free survival (PFS) and overall survival (OS).

Statistical analysis. Multivariate Cox regression analysis was performed for each outcome parameter, using a backwards elimination technique to derive a potentially suitable set of predictors. The association between NLR or PLR levels and chemotherapeutic efficacy was examined and assessed using the $\chi^{2}$ tests. For the analysis of survival data, Kaplan-Meier curves were constructed, and statistical analysis was carried out using the log-rank test. OS was defined as the time from the initiation of chemotherapy to the patient succumbing to any cause. $\mathrm{P}<0.05$ was considered to indicate statistically significant results. Statistical analyses were performed using SPSS 19.0 software (SPSS, Inc., Chicago, IL, USA).

\section{Results}

Relationship of baseline NLR and PLR levels and clinicopathologic characteristics. A low baseline NLR level correlated with improved clinicopathological characteristics, including smaller tumor size $\left(\chi^{2}=5.5456, \mathrm{P}=0.018\right)$, high differentiation $\left(\chi^{2}=5.9097, P=0.015\right)$ and less metastasis $\left(\chi^{2}=19.1809\right.$, 
Table I. Relationship between baseline NLR level and clinicopathological characteristics.

\begin{tabular}{|c|c|c|c|c|c|}
\hline \multirow[b]{2}{*}{$\begin{array}{l}\text { Clinicopathological } \\
\text { characteristics }\end{array}$} & \multicolumn{5}{|c|}{ NLR } \\
\hline & $\mathrm{n}$ & $\begin{array}{l}\text { Low } \\
\text { (n) }\end{array}$ & $\begin{array}{l}\text { High } \\
\text { (n) }\end{array}$ & $\chi^{2}$ & P-value \\
\hline
\end{tabular}

\begin{tabular}{llllll}
\hline Gender & & & & & \\
Men & 75 & 37 & 38 & 0.0356 & 0.850 \\
Women & 45 & 23 & 22 & &
\end{tabular}

Age (years)

$\begin{array}{llllll}<65 & 67 & 31 & 36 & 0.8448 & 0.358 \\ \geq 65 & 53 & 29 & 24 & & \end{array}$

Tumor size $(\mathrm{cm})$

$\begin{array}{llllll}<5 & 82 & 47 & 35 & 5.5456 & 0.018 \\ \geq 5 & 38 & 13 & 25 & & \\ \text { Lauren type } & & & & & \\ \text { Intestinal type } & 68 & 35 & 33 & 0.1357 & 0.713 \\ \text { Diffuse type } & 52 & 25 & 27 & & \end{array}$

Distant metastasis

$\begin{array}{lllrr}\text { No } & 31 & 26 & 5 & 19.1809<0.001^{\mathrm{b}} \\ \text { Yes } & 89 & 34 & 55 & \end{array}$

Degree of differentiation

$\begin{array}{llllll}\text { Highly differentiated } & 34 & 23 & 11 & 5.9097 & 0.015^{\mathrm{a}} \\ \begin{array}{l}\text { Moderately and poorly } \\ \text { differentiated }\end{array} & 86 & 37 & 49 & & \end{array}$

HER-2

\begin{tabular}{llllll}
$0-+$ & 78 & 39 & 39 & 0.000 & 1.000 \\
++-+++ & 42 & 21 & 21 & & \\
Ki-67 & & & & & \\
$<15 \%$ & 67 & 36 & 31 & 0.3580 & 0.845 \\
$\geq 15 \%$ & 53 & 24 & 29 & & \\
\hline
\end{tabular}

${ }^{\mathrm{a}} \mathrm{P}<0.05 .{ }^{\mathrm{b}} \mathrm{P}<0.01$. NLR, neutrophil to lymphocyte ratio.

$\mathrm{P}<0.001$ ) (Table I). A low baseline PLR level was also associated with less metastasis $\left(\chi^{2}=23.0083, \mathrm{P}<0.001\right)$ (Table II).

Baseline NLR and PLR levels predict chemotherapeutic efficacy. The associations between the baseline NLR or PLR level and chemotherapeutic efficacy are shown in Tables III and IV, respectively. Patients with a low baseline level of NLR or PLR had improved response to chemotherapy $\left(\chi^{2}=5.167, \mathrm{P}=0.023\right.$; $\left.\chi^{2}=7.033, \mathrm{P}=0.008\right)$, suggesting the baseline level of NLR or PLR predicts response to chemotherapy.

Baseline NLR and PLR levels predict outcomes. Median OS for all the patients was 13 months (10.45-15.55 months) with a median progression-free survival (PFS) of 5 months (4.11-5.89) (Fig. 1A and B). Follow-up for survivors was 40 months. The Kaplan-Meier plots were used to determine the effect of NLR and PLR status on OS and PFS (Fig. 1C-F). The median OS and PFS of the high NLR group were 10 months (8.23-11.77) and 3 months (2.24-3.76), respectively, while that of the low
Table II. Relationship between baseline PLR level and clinicopathological characteristics.

\begin{tabular}{|c|c|c|c|c|c|}
\hline \multirow[b]{2}{*}{$\begin{array}{l}\text { Clinicopathological } \\
\text { characteristics }\end{array}$} & \multicolumn{5}{|c|}{ PLR } \\
\hline & $\mathrm{n}$ & $\begin{array}{l}\text { Low } \\
(\mathrm{n})\end{array}$ & $\begin{array}{l}\text { High } \\
\text { (n) }\end{array}$ & $\chi^{2}$ & P-value \\
\hline \multicolumn{6}{|l|}{ Gender } \\
\hline Men & 75 & 39 & 36 & 0.320 & 0.572 \\
\hline Women & 45 & 21 & 24 & & \\
\hline \multicolumn{6}{|l|}{ Age (years) } \\
\hline$<65$ & 67 & 36 & 31 & 0.8448 & 0.358 \\
\hline$\geq 65$ & 53 & 24 & 29 & & \\
\hline \multicolumn{6}{|l|}{ Tumor size (cm) } \\
\hline$<5$ & 82 & 38 & 44 & 2.9405 & 0.086 \\
\hline$\geq 5$ & 38 & 24 & 14 & & \\
\hline \multicolumn{6}{|l|}{ Lauren type } \\
\hline Intestinal type & 68 & 32 & 36 & 0.5430 & 0.461 \\
\hline Diffuse type & 52 & 28 & 24 & & \\
\hline \multicolumn{6}{|l|}{ Distant metastasis } \\
\hline No & 31 & 4 & 27 & 23.0083 & $<0.001^{\mathrm{a}}$ \\
\hline Yes & 89 & 56 & 33 & & \\
\hline \multicolumn{6}{|l|}{ Degree of differentiation } \\
\hline Highly differentiated & 34 & 14 & 20 & 2.0906 & 0.148 \\
\hline $\begin{array}{l}\text { Moderately and poorly } \\
\text { differentiated }\end{array}$ & 86 & 48 & 38 & & \\
\hline \multicolumn{6}{|l|}{ HER-2 } \\
\hline $0-+$ & 78 & 40 & 38 & 0.1465 & 0.702 \\
\hline++-+++ & 42 & 20 & 22 & & \\
\hline \multicolumn{6}{|l|}{ Ki-67 } \\
\hline$<15 \%$ & 67 & 32 & 35 & 0.5813 & 0.304 \\
\hline$\geq 15 \%$ & 53 & 28 & 25 & & \\
\hline
\end{tabular}

${ }^{\mathrm{a}} \mathrm{P}<0.01$. PLR, platelet to lymphocyte ratio.

NLR group were 18 months (13.53-22.47) and 6 months (4.79-7.21). Significant differences were identified between the OS and PFS of the two groups $(\mathrm{P}<0.001)$. Similarly, the median OS was 10 months (8.23-11.77) in the high PLR group and 18 months $(13.53-22.48)$ in the low PLR group $(\mathrm{P}<0.001)$. The median PFS was 3 months (2.24-3.76) in the high PLR group and 6 months (4.79-7.21) in the low PLR group $(\mathrm{P}<0.001)$. Thus, the patients with higher baseline NLR and PLR levels had decreased survival ratios.

Changes in NLR and PLR levels are associated with chemotherapeutic efficacy. To determine the association between changes in the NLR or PLR level and chemotherapeutic efficacy, the blood samples were obtained and CT evaluation was performed simultaneously after the first-line chemotherapy. Forty-seven patients with a low baseline NLR level remained in this group subsequent to first-line chemotherapy (Table V). By contrast, 13 patients from this group were transferred to the high NLR level group. Twenty-four patients with a high baseline NLR level retained this 
Table III. Relationship between NLR baseline levels and chemotherapeutic efficacy.

\begin{tabular}{lcccc}
\hline NLR levels & $\begin{array}{c}\mathrm{PR}+\mathrm{SD} \\
(\mathrm{n}=76)\end{array}$ & $\begin{array}{c}\mathrm{PD} \\
(\mathrm{n}=44)\end{array}$ & $\chi^{2}$ & P-value \\
\hline Low (n=60) & 44 & 16 & 5.167 & 0.023 \\
High (n=60) & 32 & 28 & & \\
\hline
\end{tabular}

NLR, neutrophil to lymphocyte ratio. PR, partial response; SD, stable disease; PD, progressive disease.
Table IV. Relationship between PLR baseline levels and chemotherapeutic efficacy.

\begin{tabular}{lcccc}
\hline PLR levels & $\begin{array}{c}\mathrm{PR}+\mathrm{SD} \\
(\mathrm{n}=76)\end{array}$ & $\begin{array}{c}\mathrm{PD} \\
(\mathrm{n}=44)\end{array}$ & $\chi^{2}$ & P-value \\
\hline Low $(\mathrm{n}=60)$ & 45 & 15 & 7.033 & 0.008 \\
High $(\mathrm{n}=60)$ & 31 & 29 & & \\
\hline
\end{tabular}

PLR, platelet to lymphocyte ratio. PR, partial response; SD, stable disease; PD, progressive disease.
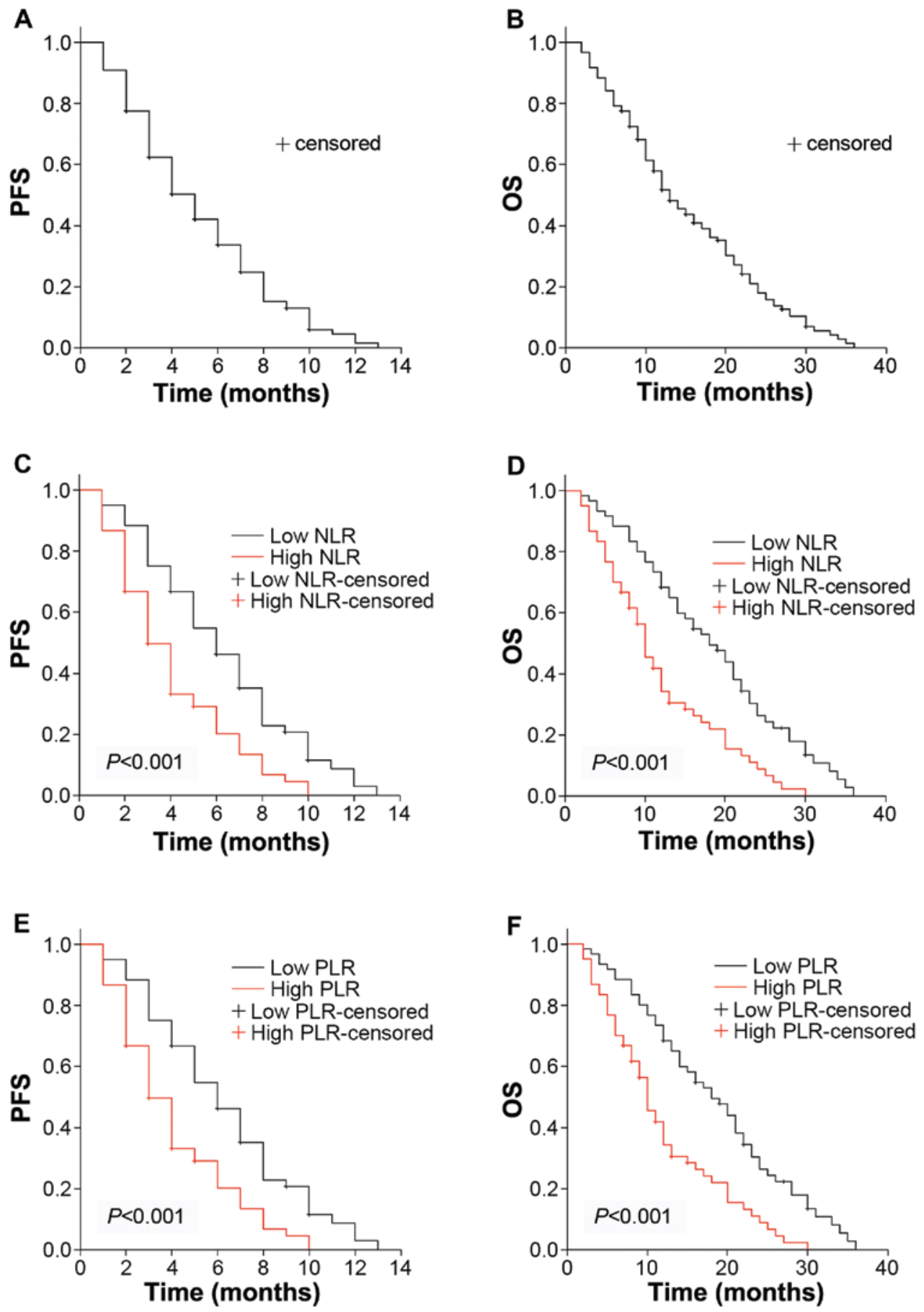

Figure 1. Association between the neutrophil to lymphocyte ratio (NLR) and platelet to lymphocyte ratio (PLR) levels and outcomes. Predicted probability of (A) progression-free survival (PFS) and (B) overall survival (OS). (C) The PFS and (D) OS according to NLR. (E) The PFS and (F) OS according to PLR. 
Table V. Relationship between changes in the NLR level and chemotherapeutic efficacy.

\begin{tabular}{|c|c|c|c|c|c|}
\hline Pre-chemotherapy & Post-chemotherapy & $P R+S D(n=76)$ & $\mathrm{PD}(\mathrm{n}=44)$ & $\chi^{2}$ & P-value \\
\hline \multirow[t]{2}{*}{ Low $(n=60)$} & Low $(n=47)$ & 39 & 8 & 4.831 & 0.0279 \\
\hline & High $(\mathrm{n}=13)$ & 7 & 6 & & \\
\hline \multirow[t]{2}{*}{ High $(n=60)$} & Low $(n=24)$ & 18 & 6 & 10.00 & 0.0016 \\
\hline & High $(n=36)$ & 12 & 24 & & \\
\hline
\end{tabular}

NLR, neutrophil to lymphocyte ratio.

Table VI. Relationship between changes in the PLR level and chemotherapeutic efficacy.

\begin{tabular}{lcccr}
\hline Pre-chemotherapy & Post-chemotherapy & PR + SD $(n=76)$ & PD (n=44) & $\chi^{2}$ \\
\hline Low $(n=60)$ & Low $(n=48)$ & 42 & 6 & 15.745 \\
High $(n=60)$ & High $(n=12)$ & 4 & 8 & $<0.001$ \\
& Low $(n=23)$ & 17 & 6 & 8.531 \\
\hline
\end{tabular}

PLR, platelet to lymphocyte ratio.

level after first-line chemotherapy. By contrast, 36 patients with a high baseline NLR level were transferred to the low NLR level group. Patients who remained in or were transferred to the low NLR level subgroup following first-line chemotherapy exhibited improved response, compared to patients who remained in or were transferred to the high NLR level group. Similar results were observed when the PLR level was investigated (Table VI).

Changes in NLR and PLR levels predict outcomes. The Kaplan-Meier plots were used to determine the effect of changes in the NLR and PLR status for OS and PFS (Fig. 2). The median OS and PFS of patients whose NLR levels increased following first-line chemotherapy were 9 months (7.07-10.93) and 3 months (2.43-3.57), respectively, while that of patients with decreased NLR were 20 months (17.25-22.75) and 7 months (5.94-8.05), respectively. Significant differences were identified for OS and PFS for the two groups $(\mathrm{P}<0.001)$. Similarly, the median OS was 9 months (7.45-10.55) in the PLR-increased group and 20 months (17.93-22.07) in the PLR-decreased group $(\mathrm{P}<0.001)$. Median PFS was 3 months (2.41-3.59) in the PLR-increased group and 7 months (6.97-9.03) in the PLR-decreased group $(\mathrm{P}<0.001)$. Thus, the patients with increased NLR and PLR levels had decreased survival ratios.

\section{Discussion}

Inflammation, recognized as the 'seventh hallmark of cancer', contributes to tumor proliferation, angiogenesis, metastasis, and resistance to hormonal and chemotherapy (23). Clinical and epidemiological studies have shown the connection between GC and chronic inflammation; thus, the pathogenesis of GC is an inflammation-driven malignancy (24-26).

Although the precise pathophysiological mechanisms involved in the association between inflammation and tumor cells remain unclear, there is growing interest in a clinical interpretation of these interactions, resulting in the establishment of novel biomarkers of cancer (27). Of these, biomarkers obtained from routine blood tests have been recently developed (15-20,28). Increased NLR and PLR levels have been shown to be correlated with the increase in cancer-associated SIR, and indicate advanced stage in several types of malignancy (29). Elevated NLR has also been shown to predict poor outcomes in colorectal cancer patients undergoing primary resection and in patients undergoing hepatectomy for liver metastases $(15,30)$. A number of studies do not support the utilization of PLR level as an independent prognostic factor of survival in contrast to NLR, which is widely accepted in the majority of relevant studies. This discrepancy may be due to the prethrombotic profile of the underlying cancer type. For cancers associated with high thrombotic risk, such as pancreatic cancer, PLR is a potential prognostic factor. However, the use of PLR as a prognostic factor may not be precise with regard to relatively hypocoagulative cancer types, such as breast cancer (11). Previous results have demonstrated that GC was hypercoagulative (31). Thus, based on previous and the present results, baseline NLR and PLR levels may be applied as biomarkers in GC. In the present study, we observed that changes of the NLR and PLR levels were consistent with chemotherapeutic efficacy and prognosis, suggesting changes in the NLR and PLR levels following treatment may also provide valuable prognostic information.

Neutrophils are actively involved in systemic and local inflammatory response via multiple mechanisms, such as releasing pro-inflammatory factors. They can promote tumor growth and metastasis by remodeling the extracellular matrix. They release reactive oxygen species (ROS), nitric oxide (NO), arginase, and suppress the T-cell response (32). Increased neutrophil count and low serum albumin levels have been shown to be the independent predictors of outcome following 

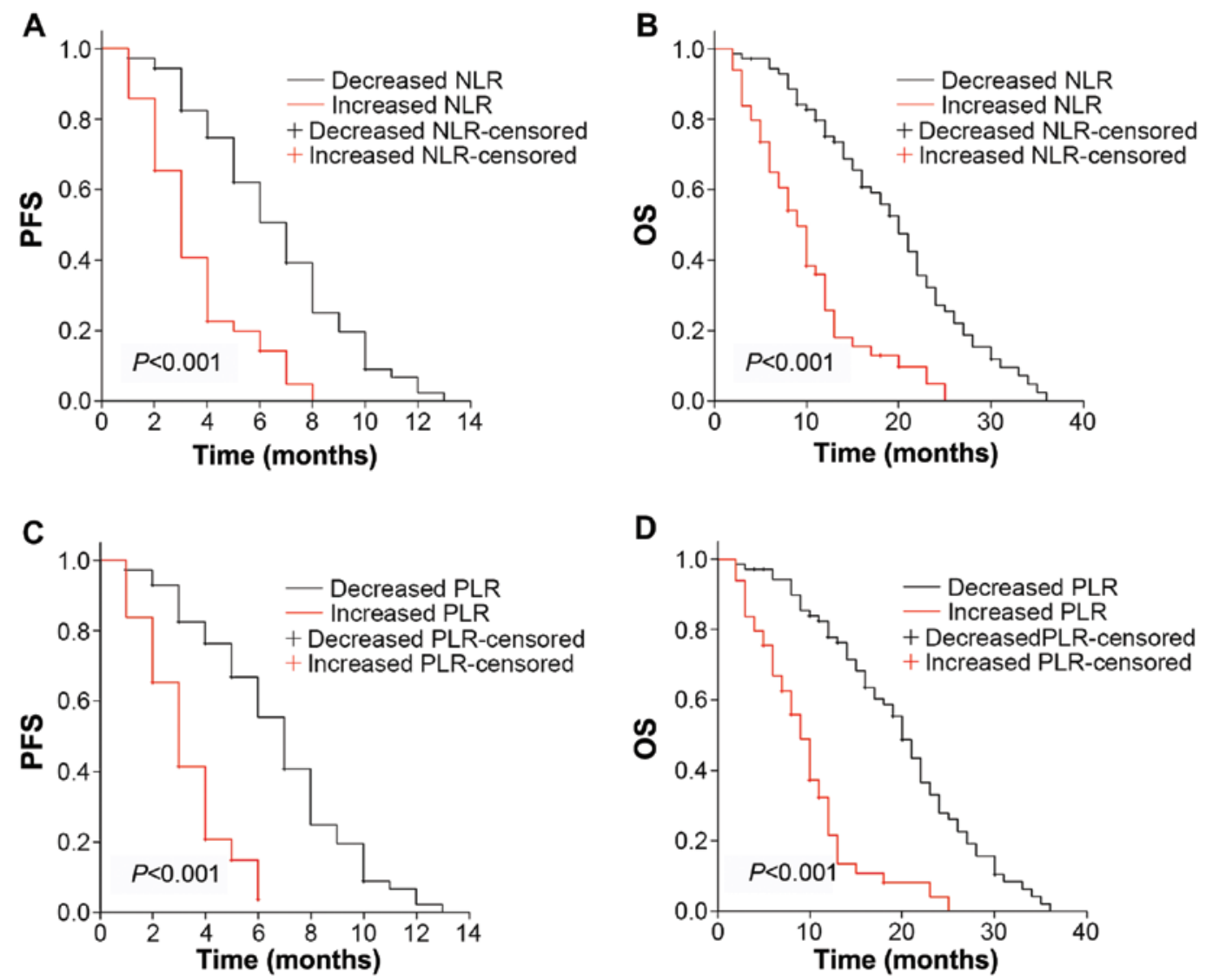

Figure 2. Relationship between changes in the neutrophil to lymphocyte ratio (NLR) and platelet to lymphocyte ratio (PLR) levels following chemotherapy and the outcomes. (A) The progression-free survival (PFS) and (B) OS according to changes in NLR. (C) The PFS and (D) OS according to changes in PLR.

hepatic resection for metastatic colorectal cancer (33). Preclinical studies have also indicated that neutrophils may act as tumor-promoting leukocytes by the transforming growth factor- $\beta$-induced signaling pathway (34).

Platelets play an important and multifaceted role in cancer progression (35). During hematogenous dissemination, the ability of circulating tumor cells to interact with platelets is believed to promote tumor cell survival within the circulation and increase the arrest of tumor cell emboli within the microcirculation $(36,37)$, thereby facilitating metastasis. Interaction with platelet is currently gaining acceptance as a key intermediate step in the process of blood-borne metastasis (35). Pre-clinical animal models have demonstrated that pharmacologically- or genetically-induced thrombocytopenia and platelet function defects are associated with reduced metastasis $(38,39)$. These observations have led to the use of antiplatelet and anticoagulation agents to prevent metastasis in experimental models and human cancer patients (35).

Besides the effects of platelets on cancer progression, counts and function of platelets may also be affected in many types of cancer. The release of pro-inflammatory cytokines by cancer cells, such as interleukin-1 (IL-1), IL-3 and IL-6, clearly promote the proliferation and differentiation of early progenitor cells, such as megakaryocyte progenitors, resulting in the gradual establishment of thrombocytosis $(40,41)$. Elevated serum concentrations of IL-6 were significantly higher in individuals with gastric, colon and prostate cancers $(42,43)$. Additionally, high levels of IL-6 and C-reactive protein play important roles in the growth process and progression of GC (44). The stimulation from cancer-released cytokines led to an increased detection of more primitive types of circulating platelets (45). Thus, the evaluation of the platelet count and functional status is consistent with the progression of malignancy $(46,47)$.

On the other hand, lymphocytes, usually $\mathrm{CD}^{+} \mathrm{T}$ cells and NK cells, possess potent anti-cancer activities that potentially affect growth and/or metastasis in various types of cancer (48). The number of lymphocytes is an undisputed prognostic marker in surgical oncology, reflecting the endogenous anticancer ability of the immune system $(49,50)$. Tumor-infiltrating lymphocytes in particular have been extensively studied, and appear to have an anti-tumorigenic role in colorectal cancer $(51,52)$. A high density of $\mathrm{CD} 8^{+} \mathrm{T}$-cell infiltration independently predicted superior survival (53).

In summary, the results of the present study explain the reason for elevated NLR and PLR enhancing malignant progression, and low levels of NLR and PLR conferring a more favorable prognosis. The normalization of NLR and PLR values after treatment may indicate resolution of intestinal inflammation. The present findings suggest that the baseline NLR and PLR levels may be used in the prediction of a chemotherapeutic response and prognosis in unresectable GC. Furthermore, changes in the NLR and PLR levels were consistent with the chemotherapeutic response and may also be useful in predicting outcomes. Considering the high GC morbidity and less developed economic condition in China, these non-invasive, convenient and inexpensive biomarkers may be beneficial with regard to the treatment of GC. 


\section{Acknowledgements}

The present study was supported by the National Natural Science Foundation of China (grant nos. 81472296, 81101867, $81272542,81200369$ and 81372443$)$, the China International Medical Foundation (grant no. CIMF-F-H001-057), the Special Foundation of Clinical Medicine of Jiangsu Provincial Bureau of Science and Technology (grant no. BL2014039), the Scientific Research Project of Jiangsu Provincial Bureau of Traditional Chinese Medicine (grant no. L213236), the Medical Scientific Research Project of Jiangsu Provincial Bureau of Health (grant no. Z201206), the Special Foundation of Wu Jieping Medical Foundation for Clinical Scientific Research (grant nos. 320.6753.1225 and 320.6750.12242), the Science and Education for Health Foundation of Suzhou for Youth (grant nos. SWKQ1003 and SWKQ1011), the Science and Technology Project Foundation of Suzhou (grant nos. SYS201112, SYSD2012137 and SYS201335), the Science and Technology Foundation of Suzhou Xiangcheng (grant nos. SZXC2012-70 and XJ201451) and a Project Founded by the Priority Academic Program Development of Jiangsu Higher Education Institutions

\section{References}

1. Jiang HB, Yang TJ, Lu P and Ma YJ: Gene expression profiling of gastric cancer. Eur Rev Med Pharmacol Sci 18: 2109-2115, 2014.

2. Li T, Chen J, Liu QL, Huo ZH and Wang ZW: Meta-analysis: E-cadherin immunoexpression as a potential prognosis biomarker related to gastric cancer metastasis in Asian patients. Eur Rev Med Pharmacol Sci 18: 2693-2703, 2014.

3. Leung WK, Wu MS, Kakugawa Y, Kim JJ, Yeoh KG, Goh KL, Wu KC, Wu DC, Sollano J, Kachintorn U, et al; Asia Pacific Working Group on Gastric Cancer: Screening for gastric cancer in Asia: Current evidence and practice. Lancet Oncol 9: 279-287, 2008.

4. Popiela T, Kulig J, Kolodziejczyk P and Sierzega M; Polish Gastric Cancer Study Group: Long-term results of surgery for early gastric cancer. Br J Surg 89: 1035-1042, 2002.

5. Forman D, Morris E, Eastwood A and Kleijnen J: Guidelines for treatment of upper gastrointestinal cancer. Lancet 361: 80, 2003.

6. Wang WH, Huang JQ, Zheng GF, Lam SK, Karlberg J and Wong BC: Non-steroidal anti-inflammatory drug use and the risk of gastric cancer: A systematic review and meta-analysis. J Natl Cancer Inst 95: 1784-1791, 2003.

7. McMillan DC: Systemic inflammation, nutritional status and survival in patients with cancer. Curr Opin Clin Nutr Metab Care 12: 223-226, 2009.

8. Schreiber RD, Old LJ and Smyth MJ: Cancer immunoediting: Integrating immunity's roles in cancer suppression and promotion. Science 331: 1565-1570, 2011.

9. Carruthers R, Tho LM, Brown J, Kakumanu S, McCartney E and McDonald AC: Systemic inflammatory response is a predictor of outcome in patients undergoing preoperative chemoradiation for locally advanced rectal cancer. Colorectal Dis 14: e701-707, 2012.

10. Kemal Y, Demirağ G, Ekiz K and Yücel I: Mean platelet volume could be a useful biomarker for monitoring epithelial ovarian cancer. J Obstet Gynaecol 34: 515-518, 2014.

11. Seretis C, Seretis F, Lagoudianakis E, Politou M, Gemenetzis G and Salemis NS: Enhancing the accuracy of platelet to lymphocyte ratio after adjustment for large platelet count: a pilot study in breast cancer patients. Int J Surg Oncol 2012: 653608, 2012.

12. Celikbilek M, Dogan S, Ozbakır O, Zararsız G, Kücük H, Gürsoy S, Yurci A, Güven K and Yücesoy M: Neutrophillymphocyte ratio as a predictor of disease severity in ulcerative colitis. J Clin Lab Anal 27: 72-76, 2013.

13. Imtiaz F, Shafique K, Mirza SS, Ayoob Z, Vart P and Rao S: Neutrophil lymphocyte ratio as a measure of systemic inflammation in prevalent chronic diseases in Asian population. Int Arch Med 5: 2, 2012.
14. Tousoulis D, Antoniades C, Koumallos N and Stefanadis C: Pro-inflammatory cytokines in acute coronary syndromes: From bench to bedside. Cytokine Growth Factor Rev 17: 225-233, 2006.

15. Walsh SR, Cook EJ, Goulder F, Justin TA and Keeling NJ: Neutrophil-lymphocyte ratio as a prognostic factor in colorectal cancer. J Surg Oncol 91: 181-184, 2005.

16. Gwak MS, Choi SJ, Kim JA, Ko JS, Kim TH, Lee SM, Park JA and Kim MH: Effects of gender on white blood cell populations and neutrophil-lymphocyte ratio following gastrectomy in patients with stomach cancer. J Korean Med Sci 22 (Suppl): S104-S108, 2007.

17. Sharaiha RZ, Halazun KJ, Mirza F, Port JL, Lee PC, Neugut AI, Altorki NK and Abrams JA: Elevated preoperative neutrophil: lymphocyte ratio as a predictor of postoperative disease recurrence in esophageal cancer. Ann Surg Oncol 18: 3362-3369, 2011.

18. Thavaramara T, Phaloprakarn C, Tangjitgamol S and Manusirivithaya S: Role of neutrophil to lymphocyte ratio as a prognostic indicator for epithelial ovarian cancer. J Med Assoc Thai 94: 871-877, 2011.

19. Kemal Y, Yucel I, Ekiz K, Demirag G, Yilmaz B, Teker F and Ozdemir M: Elevated serum neutrophil to lymphocyte and platelet to lymphocyte ratios could be useful in lung cancer diagnosis. Asian Pac J Cancer Prev 15: 2651-2654, 2014.

20. Azab B, Bhatt VR, Phookan J, Murukutla S, Kohn N, Terjanian T and Widmann WD: Usefulness of the neutrophil-to-lymphocyte ratio in predicting short- and long-term mortality in breast cancer patients. Ann Surg Oncol 19: 217-224, 2012.

21. Proctor MJ, Morrison DS, Talwar D, Balmer SM, Fletcher CD, O'Reilly DS, Foulis AK, Horgan PG and McMillan DC: A comparison of inflammation-based prognostic scores in patients with cancer. A Glasgow Inflammation Outcome Study. Eur J Cancer 47: 2633-2641, 2011.

22. Eisenhauer EA, Therasse P, Bogaerts J, Schwartz LH, Sargent D, Ford R, Dancey J, Arbuck S, Gwyther S, Mooney M, et al: New response evaluation criteria in solid tumours: Revised RECIST guideline (version 1.1). Eur J Cancer 45: 228-247, 2009.

23. Wu Y and Zhou BP: Inflammation: A driving force speeds cancer metastasis. Cell Cycle 8: 3267-3273, 2009.

24. Ilhan N, Ilhan N, Ilhan Y, Akbulut H and Kucuksu M: C-reactive protein, procalcitonin, interleukin-6, vascular endothelial growth factor and oxidative metabolites in diagnosis of infection and staging in patients with gastric cancer. World J Gastroenterol 10: 1115-1120, 2004.

25. Lochhead P and El-Omar EM: Gastric cancer. Br Med Bull 85: 87-100, 2008.

26. Hussain SP and Harris CC: Inflammation and cancer: an ancient link with novel potentials. Int J Cancer 121: 2373-2380, 2007.

27. Aliustaoglu M, Bilici A, Ustaalioglu BB, Konya V, Gucun M, Seker M and Gumus M: The effect of peripheral blood values on prognosis of patients with locally advanced gastric cancer before treatment. Med Oncol 27: 1060-1065, 2010.

28. Smith RA, Bosonnet L, Raraty M, Sutton R, Neoptolemos JP, Campbell F and Ghaneh P: Preoperative platelet-lymphocyte ratio is an independent significant prognostic marker in resected pancreatic ductal adenocarcinoma. Am J Surg 197: 466-472, 2009.

29. Raungkaewmanee S, Tangjitgamol S, Manusirivithaya S, Srijaipracharoen $\mathrm{S}$ and Thavaramara T: Platelet to lymphocyte ratio as a prognostic factor for epithelial ovarian cancer. J Gynecol Oncol 23: 265-273, 2012.

30. Malik HZ, Prasad KR, Halazun KJ, Aldoori A, Al-Mukhtar A, Gomez D, Lodge JP and Toogood GJ: Preoperative prognostic score for predicting survival after hepatic resection for colorectal liver metastases. Ann Surg 246: 806-814, 2007.

31. Heras P, Hatzopoulos A, Kritikos N and Kritikos K: Platelet count and tumor progression in gastric cancer patients. Scand J Gastroenterol 45: 1005-1006, 2010

32. De Larco JE, Wuertz BR and Furcht LT: The potential role of neutrophils in promoting the metastatic phenotype of tumors releasing interleukin-8. Clin Cancer Res 10: 4895-4900, 2004.

33. Neal CP, Mann CD, Sutton CD, Garcea G, Ong SL, Steward WP, Dennison AR and Berry DP: Evaluation of the prognostic value of systemic inflammation and socioeconomic deprivation in patients with resectable colorectal liver metastases. Eur J Cancer 45: 56-64, 2009.

34. Suzuki K, Kachala SS, Kadota K, Shen R, Mo Q, Beer DG, Rusch VW, Travis WD and Adusumilli PS: Prognostic immune markers in non-small cell lung cancer. Clin Cancer Res 17: 5247-5256, 2011 
35. Lian L, Li W, Li ZY, Mao YX, Zhang YT, Zhao YM, Chen K, Duan WM and Tao M: Inhibition of MCF-7 breast cancer cellinduced platelet aggregation using a combination of antiplatelet drugs. Oncol Lett 5: 675-680, 2013.

36. Egan K, Crowley D, Smyth P, O'Toole S, Spillane C, Martin C, Gallagher M, Canney A, Norris L, Conlon N, et al: Platelet adhesion and degranulation induce pro-survival and proangiogenic signalling in ovarian cancer cells. PLoS One 6: e26125, 2011.

37. Tsuruo $\mathrm{T}$ and Fujita $\mathrm{N}$ : Platelet aggregation in the formation of tumor metastasis. Proc Jpn Acad, Ser B, Phys Biol Sci 84 189-198, 2008.

38. Camerer E, Qazi AA, Duong DN, Cornelissen I, Advincula R and Coughlin SR: Platelets, protease-activated receptors, and fibrinogen in hematogenous metastasis. Blood 104: 397-401, 2004.

39. Jain S, Zuka M, Liu J, Russell S, Dent J, Guerrero JA, Forsyth J, Maruszak B, Gartner TK, Felding-Habermann B, et al: Platelet glycoprotein $\mathrm{Ib}$ alpha supports experimental lung metastasis. Proc Natl Acad Sci USA 104: 9024-9028, 2007.

40. Klinger MH and Jelkmann W: Role of blood platelets in infection and inflammation. J Interferon Cytokine Res 22: 913-922, 2002.

41. Alexandrakis MG, Passam FH, Moschandrea IA Christophoridou AV, Pappa CA, Coulocheri SA and Kyriakou DS: Levels of serum cytokines and acute phase proteins in patients with essential and cancer-related thrombocytosis. Am J Clin Oncol 26: 135-140, 2003.

42. Galizia G1, Lieto E, De Vita F, Romano C, Orditura M, Castellano P, Imperatore V, Infusino S, Catalano G and Pignatelli C: Circulating levels of interleukin-10 and interleukin-6 in gastric and colon cancer patients before and after surgery: relationship with radicality and outcome. J Interferon Cytokine Res 22: 473-482, 2002.

43. Shariat SF, Andrews B, Kattan MW, Kim J, Wheeler TM and Slawin KM: Plasma levels of interleukin-6 and its soluble receptor are associated with prostate cancer progression and metastasis. Urology 58: 1008-1015, 2001.

44. Kim DK, Oh SY, Kwon HC, Lee S, Kwon KA, Kim BG, Kim SG, Kim SH, Jang JS, Kim MC, et al: Clinical significances of preoperative serum interleukin-6 and C-reactive protein level in operable gastric cancer. BMC Cancer 9: 155, 2009.
45. Khandekar MM, Khurana AS, Deshmukh SD, Kakrani AL, Katdare AD and Inamdar AK: Platelet volume indices in patients with coronary artery disease and acute myocardial infarction: An Indian scenario. J Clin Pathol 59: 146-149, 2006.

46. Hurst NJ Jr, Najy AJ, Ustach CV, Movilla L and Kim HR: Platelet-derived growth factor-C (PDGF-C) activation by serine proteases: Implications for breast cancer progression. Biochem J 441: 909-918, 2012.

47. Bambace NM and Holmes CE: The platelet contribution to cancer progression. J Thromb Haemost 9: 237-249, 2011.

48. Ohashi R, Takahashi K, Miura K, Ishiwata T, Sakuraba S and Fukuchi Y: Prognostic factors in patients with inoperable non-small cell lung cancer - an analysis of long-term survival patients. Gan To Kagaku Ryoho 33: 1595-1602, 2006.

49. Milne K, Alexander C, Webb JR, Sun W, Dillon K, Kalloger SE, Gilks CB, Clarke B, Köbel M and Nelson BH: Absolute lymphocyte count is associated with survival in ovarian cancer independent of tumor-infiltrating lymphocytes. J Transl Med 10: 33, 2012.

50. Kobayashi N, Usui S, Kikuchi S, Goto Y, Sakai M, Onizuka M and Sato Y: Preoperative lymphocyte count is an independent prognostic factor in node-negative non-small cell lung cancer. Lung Cancer 75: 223-227, 2012.

51. Ohtani H: Focus on TILs: Prognostic significance of tumor infiltrating lymphocytes in human colorectal cancer. Cancer Immun 7: 4, 2007.

52. Galon J, Costes A, Sanchez-Cabo F, Kirilovsky A, Mlecnik B, Lagorce-Pagès $\mathrm{C}$, Tosolini $\mathrm{M}$, Camus $\mathrm{M}$, Berger $\mathrm{A}$, Wind $\mathrm{P}$, et al: Type, density, and location of immune cells within human colorectal tumors predict clinical outcome. Science 313: 1960-1964, 2006.

53. Mlecnik B, Tosolini M, Kirilovsky A, Berger A, Bindea G, Meatchi T, Bruneval P, Trajanoski Z, Fridman WH, Pagès F, et al: Histopathologic-based prognostic factors of colorectal cancers are associated with the state of the local immune reaction. J Clin Oncol 29: 610-618, 2011 